2. Кларин М. В. Педагогические технологии в учебном процессе. Анализ зарубежного опыта / М. В. Кларин. - Москва : Знание, 1989. - 80 с.

УДК $378.016: 537.8$

Олександр Коновал

\title{
СУПЕРЕЧНОСТІ У ТРАДИЦІЙНЙ МЕТОДИЦІ НАВЧАННЯ ЕЛЕКТРОДИНАМІКИ
}

Коновал О. А. Суперечності у традиційній методиці навчання електродинаміки.

У статті здійснено теоретичний аналіз традиційних підходів до вивчення електродинаміки, звернуто увагу на суперечності, які виникають під час застосування класичного закону Біо-Савара i вибору умови нейтральності провідника 3 постійним струмом.

Ключові слова: закон Біо-Савара, умова нейтральності провідника 3 постійним струмом, методика навчання електродинаміки.

Коновал О. А. Противоречия в традиционной методике преподавания электродинамики.

В статье осуществлен теоретический анализ традиционных подходов к преподаванию электродинамики, обращено внимание на противоречия, которые возникают при применении классического закона Био-Савара и условия нейтральности проводника с постоянным током.

Ключевые слова: закона Био-Савара, условие нейтральности проводника с постоянным током, методика преподавания электродинамики.

Konoval A. A. Contradictions in the traditional methods in teaching electrodynamics.

The article deals with the theoretical analysis of the traditional approaches to electrodynamics teaching. The author has paid attention to the contradictions arising in the process of application of the classical Biot-Savart`s law and the neutrality conditions of the conductor with a constant current.

Key words: Biot-Savart's law, neutrality condition of the conductor with a constant current, teaching methods of electrodynamics.

Розвиток сучасної фізичної науки висуває низку нових вимог до фахової підготовки студентів-фізиків, що потребує оволодіння ними системою сучасних наукових знань. Виконання цих вимог стає можливим за умови вдосконалення методики вивчення фізики на засадах принципу фундаменталізації (ПФ).

Однак звернення до сучасних посібників з теоретичної фізики та загального курсу фізики [1-14], шкільного курсу фізики засвідчує, що в інтерпретації окремих законів, питань в методиці навчання електродинаміки мають місце суперечності та питання дискусійного характеру, які заважають формуванню у студентів цілісної картини адекватних уявлень щодо системи основних законів електродинаміки. Наш багаторічний досвід засвідчує, що наявність цих суперечностей викликає особливі труднощі у студентів при самостійному опрацюванні навчального матеріалу.

У зв'язку з цим метою статті визначено: здійснення теоретичного аналізу сучасних методичних підходів у процесі викладання електродинаміки, виявлення суперечностей i проблемних питань у теорії та методиці навчання електродинаміки й окреслення перспектив їх розв'язання. 
Передбачається, що ознайомлення студентів із виявленими суперечностями у процесі самостійної роботи за запропонованою нижче логікою сприятиме формуванню системних знань з електродинаміки і дозволить майбутнім учителям фізики використовувати їх під час вибору варіантів методики ії навчання.

Ураховуючи обмеженість обсягу наукової статті, зупинимося більш детально на аналізі низки суперечностей, які пов'язані з законом Біо-Савара, залишивши перспективою подальших наукових розвідок більш грунтовне дослідження причин інших суперечностей та дискусійних питань, що мають місце в теорії та методиці навчання електродинаміки.

Звернувшись наразі до аналізу інтерпретації закону Біо-Савара, звернемо, по-перше, увагу на розмаїття підходів до трактування статусу цього закону [1]:

$$
d \vec{B}=\frac{\mu_{0}}{4 \pi} \cdot \frac{i \cdot\lfloor d \vec{l}, \vec{r}]}{r^{3}},
$$

де $\vec{r}$ - радіус-вектор проведений від елемента струму $i d \vec{l}$ в дану точку простору, $d \vec{B}$ - значення індукції магнітного поля, що створене елементом струму $i d \vec{l}$ у даній точці простору.

Із огляду, поданому нами в монографії [1, с. 98], маємо такі точки зору щодо статусу закону Біо-Савара:

a) закон Біо-Савара $є$ незалежним і фундаментальним експериментальним законом [2; 8; 9];

б) закон Біо-Савара - це наслідок формули Ампера-Грассмана [3], а формула АмпераГрассмана є вихідним фундаментально-дослідним положенням магнітостатики;

в) закон Біо-Савара в принципі не може бути незалежним і дослідно-фундаментальним, оскільки елемент струму $i d \vec{l}$ не може бути реалізованим як самостійна структура [4, с. 221], а його використання передбачає, перш за все, процедуру обгрунтування. Мабуть, уперше на цю обставину щодо статусу цього закону наголос зроблено в посібнику проф. А. В. Желеховського [5];

г) закон Біо-Савара може бути обгрунтований на основі правдоподібних i суперечливих міркувань [6; 7; 8], які не мають доказової сили;

г) цей закон розглядається як результат узагальнення дослідних даних [8; 9; 10];

д) закон Біо-Савара в інтегральній формі (4) є наслідком рівнянь Максвелла [11; 12], і тому не виникає потреби в його обгрунтуванні;

е) закон Біо-Савара розглядається як наслідок виразу для індукції магнітного поля (в нерелятивістському наближенні) зарядженої частинки (ЗЧ), що рухається з $\vec{v}=$ const i принципу суперпозиції магнітних полів [4, с. 221].

Варто наголосити на тому, що значна кількість авторів посібників і статей на цю тему підкреслювали суперечливість і непослідовність зазначених поглядів та методик вивчення магнітного поля постійних і квазістаціонарних струмів.

При цьому відчувався їх власний дискомфорт і певна розгубленість під час опису та пояснення основ магнітостатики, про що свідчить непослідовна й суперечлива аргументація щодо обгрунтування закону Біо-Савара такими численними способами.

I все ж закон Біо-Савара в більшості навчально-методичних виданнях уважається фундаментальним. Основний аргумент, який доводить таку точку зору, полягає в тому, що результати розрахунків, виконаних на його основі, підтверджуються в дослідах.

Але виходячи із принцииу фундаментальності, навіщо співвідношення, яке не 
встановлене прямим експериментом, $і$ яке 6 , або може бути наслідком інших принципів, підносити до рангу фундаментального і незалежного!?

Незважаючи на розуміння того, що закон (1) принципово недоступний дослідній перевірці, закон Біо-Савара у переважній більшості сучасних навчально-методичних посібників тлумачиться як експериментальний закон.

Аналіз суті цього закону та історичних джерел свідчить про некоректність такого підходу під час вивчення та інтерпретації співвідношення (1) [1].

По-друге, наші дослідження показали, що в деяких випадках застосування закону (1) призводить до результатів, що суперечать основним положенням релятивістської електродинаміки [1].

Якщо припустити (і це досить правдоподібно), що всі електрони в металевому провіднику, які реалізують елемент струму $i d \vec{l}=-q \vec{v} N$, рухаються 3 однаковою швидкістю $\vec{v}$, то із (1) та принципу суперпозиції, одержуємо вираз для індукції магнітного поля (МП), яке створюється однією рухомою зарядженою частинкою (3Ч) $[1 ; 2 ; 3]$ :

$$
\vec{B}_{1}=\frac{\mu_{0} q}{4 \pi r^{3}} \cdot[\vec{v}, \vec{r}]=\mu_{0} \varepsilon_{0}\left[\vec{v}, \frac{q \vec{r}}{4 \pi \varepsilon_{0} r^{3}}\right]=\mu_{0} \varepsilon_{0}[\vec{v}, \vec{E}],
$$

де $\vec{E}=\frac{q \vec{r}}{4 \pi \varepsilon_{0} r^{3}} \quad$ - напруженість електричного поля, що створюється (в нерелятивістському наближенні) рухомою ЗЧ у відповідній точці поля.

Звернемо увагу на низку суперечностей, які виникають при застосуванні закону Біо-

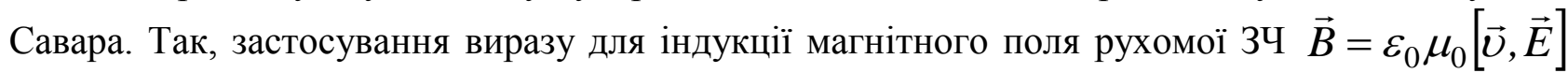
(який може розглядатися як наслідок закону (6)) та виразу $\vec{E}=\frac{q \vec{r}}{4 \pi \varepsilon_{0} r^{3}}$ для аналізу однієї і тієї ж електродинамічної задачі приводить до висновків, що суперечать принципу відносності.

Дійсно, розглянемо уявний експеримент, схема якого зображена на рис. 1.

Згідно 3 традиційною інтерпретацією явища електромагнітної індукції (ЕMI), в контурі, внаслідок зміни за часом індукції магнітного поля в кожній точці плоскої поверхні, обмеженої контуром $L$ (а, отже, і зміни магнітного потоку в часі), виникне ЕРС індукції.

Але такий висновок суперечить принципу відносності: при переході в систему відліку, яка зв'язана з ЗЧ, контур буде рухатися в центрально-симетричному кулонівському полі. Таке поле потенціальне, тому відсутні фізичні причини, які могли б породжувати ЕРС в контурі $L$.

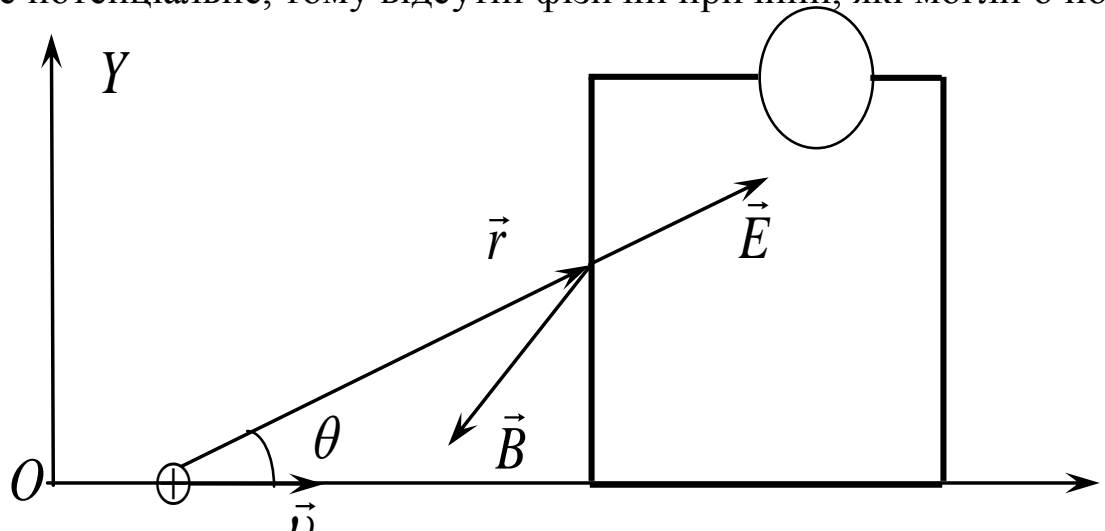

Рис. 1. Схема уявного експерименту по визначенню ЕРС індукції в контурі $L$. ЗЧ рухається з постійною швидкістю $\vec{v}$ в площині контуру $L$. 
Аналогічно, у прикладах, які зображені на рис. 2 і рис. 3, використання класичного закону Біо-Савара (1) призводить до результату, що суперечить принципу відносності.

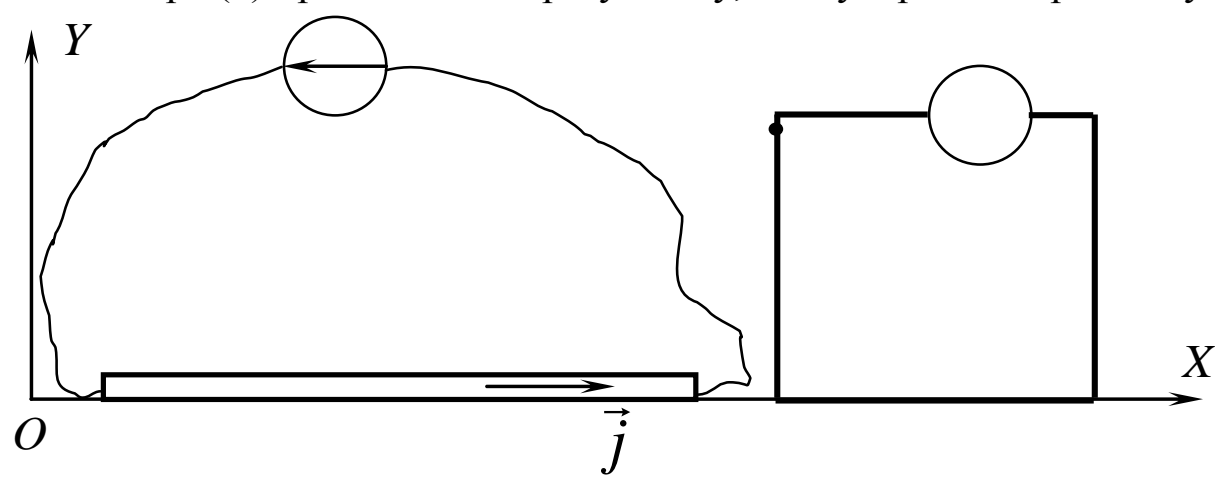

Рис. 2. У дротяному в контурі $L_{1}$, який знаходиться поряд з нескінченно довгим провідником з постійним струмом, ЕРС відсутня

Згідно з законом Біо-Савара (1) і традиційною інтерпретацією явища EMI, в контурі $L_{1}$ (див. приклади, які показані на рис. 2 та рис. 3) слід чекати появу певної ЕРС індукції. Такий висновок випливає із таких міркувань.

Кожний із електронів провідності, який рухається 3 дрейфовою швидкістю у провідниках електричного кола, створює в кожній точці плоскої поверхні, обмеженої контуром $L_{1}$, змінне магнітне поле. Це змінне магнітне поле в свою чергу в кожній точці поверхні породжує вихрове електричне поле $(\operatorname{rot} \vec{E} \neq 0)$. Інтегральний ефект повинен виявитися у виникненні індукційного струму в контурі $L_{1}$. Але досліди показують, що ЕРС в контурі $L_{1}$ не виникає.

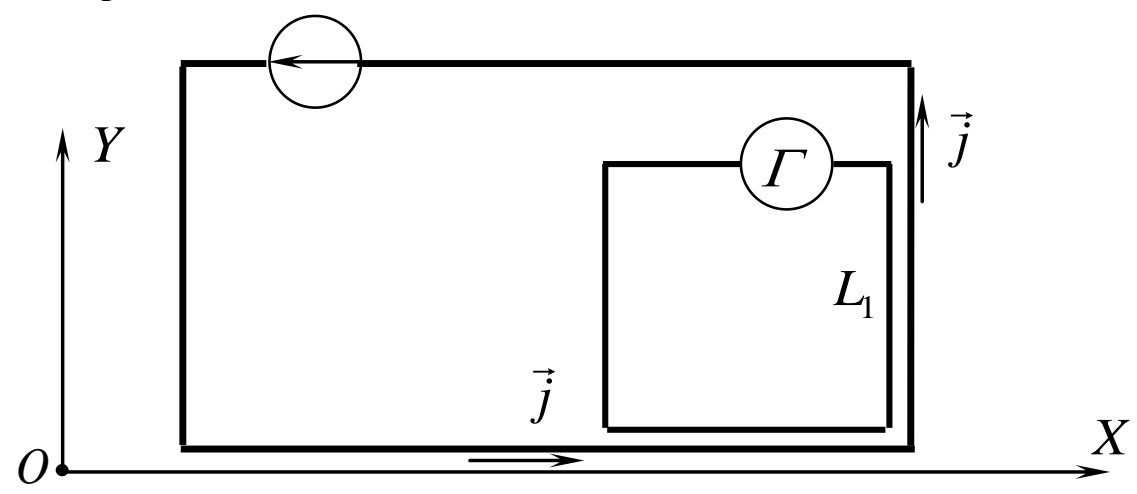

Рис. 3. У дротяному в контурі $L_{1}$, який знаходиться поряд з колом постійного струму, ЕРС відсутня

Отже, застосування закону (1) та його еквіваленту - виразу для індукції МП, яке породжується окремою рухомою ЗЧ $-\vec{B}_{1}=\varepsilon_{0} \mu_{0}[\vec{v}, \vec{E}]=\frac{\mu_{0} q \cdot[\vec{v}, \vec{r}]}{4 \pi r^{3}}$ в подібних задачах дає результат, що суперечить фізичній реальності.

Таким чином, закон Біо-Савара і формула $\vec{E}=\frac{q \vec{r}}{4 \pi \varepsilon_{0} r^{3}}$ (закон Кулона), несумісні між собою для одночасного використання при аналізі однієї і тієї ж електродинамічної задачі, оскільки призводять до принципово помилкових висновків і протиріч [2]. 
Отже, традиційна методика вивчення електродинаміки, заснована, зокрема, і на класичному законі Біо-Савара не може пояснити відсутність ЕРС в контурах на рисунках 1, 2, 3. Однак у стандартних посібниках і в науково-методичних публікаціях ці дві формули використовуються разом, що $\epsilon$, з нашої точки зору, фізичною помилкою.

У той же час закон Біо-Савара може розглядатися як наслідок рівняння Максвелла $\operatorname{rot} \vec{B}=\mu_{0} \vec{j}$.

Дійсно, вектор-потенціал $\vec{A}(\vec{r})=\frac{\mu_{0}}{4 \pi} \int_{V^{\prime}} \frac{\vec{j}\left(\vec{r}^{\prime}\right) d V^{\prime}}{R} \in$ розв'язком рівняння Пуассона для векторного потенціалу:

$$
\nabla^{2} \vec{A}=-\mu_{0} \vec{j}
$$

де $\vec{j}\left(\vec{r}^{\prime}\right)$ - густина струмів провідності в просторовій області $V^{\prime}$ (рис. 4$)$.

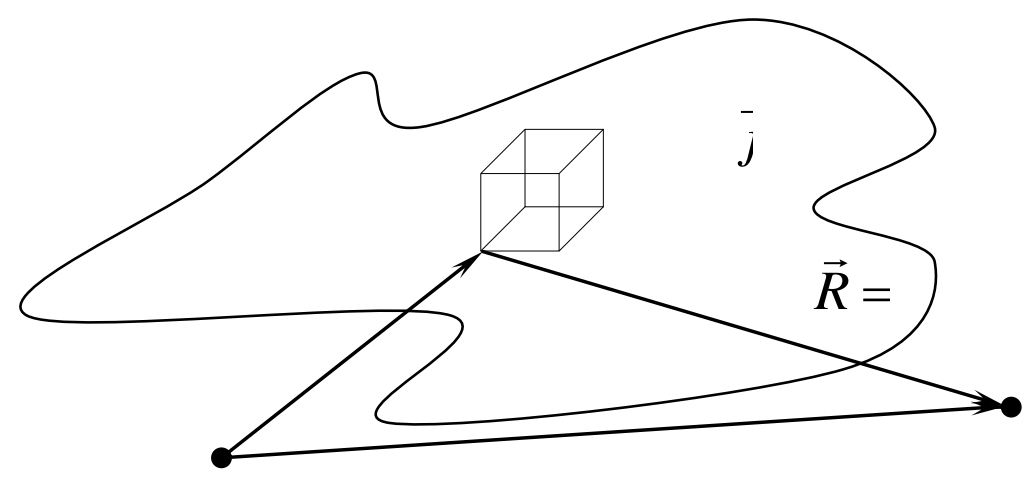

Рис. 4. Знаходження векторного потенціалу $\vec{A}(\vec{r})$ та індукції магнітного поля в т. Р, що створюються постійними струмами, розподіленими в об'ємі $V^{\prime}$

Тоді $\vec{B}(\vec{r})=\operatorname{rot} A(\vec{r})=\operatorname{rot} \frac{\mu_{0}}{4 \pi} \int_{V^{\prime}} \frac{\vec{j}\left(\vec{r}^{\prime}\right) d V^{\prime}}{R}=\frac{\mu_{0}}{4 \pi} \int_{V^{\prime}} \operatorname{rot} \frac{\vec{j}\left(\vec{r}^{\prime}\right) d V^{\prime}}{R}$.

Використовуючи формулу векторного аналізу:

$$
\operatorname{rot}(u \vec{a})=u \cdot \operatorname{rot} \vec{a}+[\operatorname{gradu}, \vec{a}],
$$

де $u(\vec{r})$ - довільна скалярна функція, підінтегральний вираз (3) набуває вигляду:

$$
\operatorname{rot} \frac{\vec{j}\left(\vec{r}^{\prime}\right)}{R}=\frac{1}{R} \operatorname{rotj}\left(\vec{r}^{\prime}\right)+\left[\operatorname{grad} \frac{1}{R}, \vec{j}\left(\vec{r}^{\prime}\right)\right]=\left[\operatorname{grad} \frac{1}{R}, \vec{j}\left(\vec{r}^{\prime}\right)\right]=\frac{\left[\vec{j}\left(\vec{r}^{\prime}\right), \vec{R}\right]}{R^{3}}
$$

оскільки $\operatorname{grad} \frac{1}{R}=-\frac{\vec{R}}{R^{3}}$.

Тобто отримуємо [11, с. 81$]$ :

$$
\vec{B}(\vec{r})=\frac{\mu_{0}}{4 \pi} \int_{V^{\prime}} \frac{\left[\vec{j}\left(\vec{r}^{\prime}\right), \vec{R}\right]}{R^{3}} d V^{\prime}
$$


Із закону $\vec{B}(\vec{r})=\frac{\mu_{0}}{4 \pi} \int_{V^{\prime}} \frac{\left[\vec{j}\left(\vec{r}^{\prime}\right), \vec{R}\right]}{R^{3}} d V^{\prime}$ одержується, у випадку лінійних струмів, закон Біо-Савара в диференціальній формі:

$$
d \vec{B}=\frac{\mu_{0} i}{4 \pi r^{3}} \cdot[d \vec{l}, \vec{r}]
$$

і який суперечить в деяких задачах, як ми впевнилися вище, принципу відносності.

Але як з позицій логіки фізичної науки на засадах ПФ узгодити взаємопротилежні точки зору:

а) рівняння Максвелла релятивістськи коваріантні (тобто рівняння Максвелла не суперечать принципу відносності А. Ейнштейна), й з них виходить як наслідок закон БіоСавара;

б) закон Біо-Савара $d \vec{B}=\frac{\mu_{0} i}{4 \pi r^{3}} \cdot[d \vec{l}, \vec{r}]$ та закон Кулона $\vec{E}=\frac{q \vec{r}}{4 \pi \varepsilon_{0} r^{3}}$, які в навчально-методичній літературі часто застосовуються разом, несумісні між собою та суперечать принципу відносності. Використання їх одночасно під час аналізу електромагнітних явищ призводить до принципово хибних висновків і суперечностей.

У посібнику [11] стверджується, що подібні викладки, і зокрема, у такий спосіб одержаний закон Біо-Савара є наближеними. Наближеними в тому сенсі, що в рівнянні Максвелла $\operatorname{rot} \vec{B}=\mu_{0} \vec{j}$ начебто нехтується струмами зміщення [11, с. 79]. Але яке відношення мають струми зміщення до рівняння Максвелла для постійних струмів $\operatorname{rot} \vec{B}=\mu_{0} \vec{j}$ в традиційному розумінні цього рівняння?!

Звернемося тепер до аналізу ще одного яскравого протиріччя, наявного в методиці вивчення електродинаміки [1].

Для аналізу умови нейтральності ППС з урахуванням зміни густини зарядів сукупності електронів провідності й іонів кристалічної гратки внаслідок руху їх з різними швидкостями в деякій системи відліку розглянемо модель провідника з постійним струмом (ППС), яка часто використовується в навчальних посібниках $[1-4 ; 6 ; 12 ; 13]$ (рис. 5).

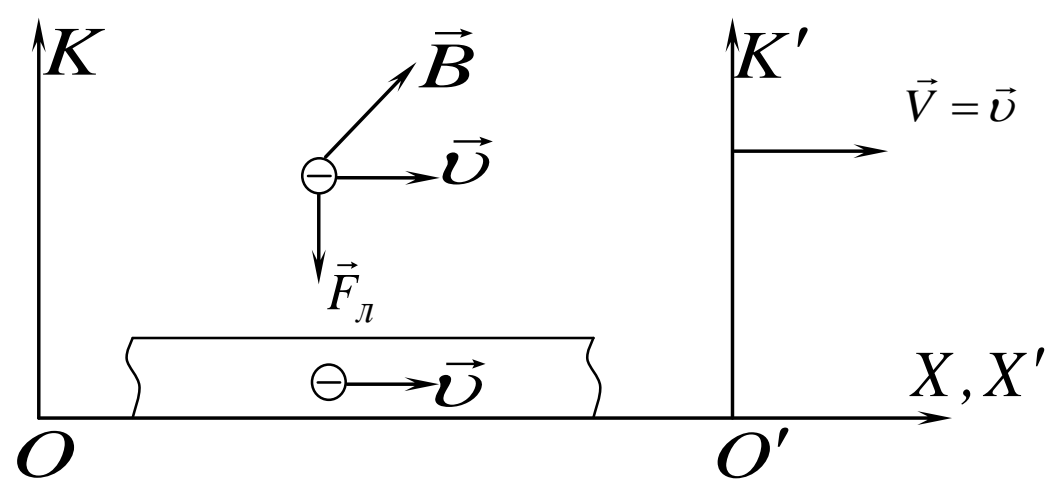

Рис. 5. Взаємодія електрона і ППС в СВ $K$ і СВ $K^{\prime}$

Нехай у системі відліку $K$ вздовж вісі $O X$ знаходиться нерухомий циліндричний ППС, по якому протікає постійний струм густиною $\boldsymbol{j}_{x}=\boldsymbol{P} \cdot \boldsymbol{U}$. Система відліку $K^{\prime}$ 
рухається зі швидкістю $\vec{V}=\vec{v}$ вздовж осі $O X \mathrm{CB} K$.

Традиційно, за Р. Фейнманом, умову нейтральності нерухомого ППС у СВ $K[3 ; 12$; 13] визначають так:

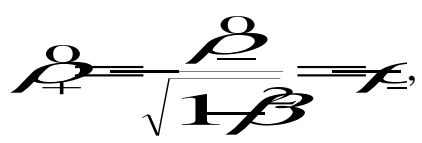

де $\boldsymbol{\rho}=\frac{\boldsymbol{\rho}}{\sqrt{\mathbf{1 - \mathcal { \beta }}}}-$ об'ємна густина заряду електронів провідності в системі відліку $K$, в якій провідник нерухомий, $v$ - дрейфова швидкість електронів провідності, $\beta=\frac{v}{c}, c$ - швидкість світла у вакуумі, $\rho_{-}^{0}, \rho_{+}^{0}$ - густини зарядів електронів провідності і позитивних іонів у власних системах відліку відповідно.

Тоді електричне поле у СВ $K^{\prime}$ буде створюватися некомпенсованими густинами зарядів іонів та електронів провідності. Оскільки електрони в СВ $K^{\prime}$ нерухомі, а іони

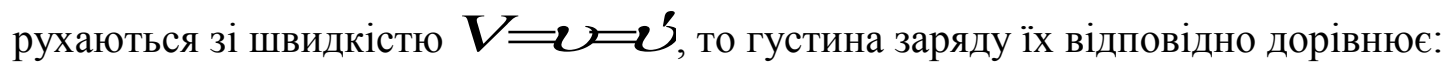

$$
\rho_{-}^{\prime}=\rho_{-}^{0}=\rho_{-} \sqrt{1-\beta^{2}}, \rho_{+}^{\prime}=\frac{\rho_{+}^{0}}{\sqrt{1-\beta^{2}}} .
$$

А тому об'ємна густина заряду ППС у СВ $K^{\prime}$ буде такою:

$$
\rho^{\prime}=\rho_{+}^{\prime}+\rho_{-}^{\prime}=\frac{\rho_{+}^{0}}{\sqrt{1-\beta^{2}}}-\rho_{-} \sqrt{1-\beta^{2}}=\frac{\rho_{+}^{0} \beta^{2}}{\sqrt{1-\beta^{2}}} .
$$

Мабуть, уперше на суперечливість умови нейтральності (5) звернуто увагу в роботі Г. Ніколаєва [14]: оскільки СВ $K$ і СВ $K^{\prime}$ рівноправні, то при $\vec{V}=\vec{v}$ завдяки симетричним умовам, якими визначається рух електронів провідності й іонів відповідно у СВ $K$ й у СВ $K^{\prime}$, фізичні ситуації у цих СВ повинні бути однаковими.

Окрім того очевидно, що за умови (5), нерухома, як ціле, сукупність електронів провідності має меншу густину заряду, ніж густина заряду цієї ж сукупності електронів, але рухомої (при протіканні струму) $\rho_{-}^{0}<\frac{\rho_{-}^{0}}{\sqrt{1-\beta^{2}}}=\rho_{-}$.

Але тоді при $\beta=0$ (струм у провіднику відсутній) $\rho_{-}^{0}=\rho_{-}<\rho_{+}^{0}$, тобто провідник без струму (після того, як вимкнули струм) буде заряджений позитивно: $\rho_{+}^{0}-\rho_{-}^{0}=\rho_{+}^{0}\left(1-\sqrt{1-\beta^{2}}\right)$.

Невже величина цього заряду залежить від сили струму, що протікав раніше ?! Як це треба розуміти?

Отже, виникає суперечність, розв'язання якої, на наш погляд, $є$ важливим дидактичним засобом активізації механізмів мисленнєвої діяльності студентів. Роздуми студентів можна посилити зверненням до аналізу наявних у науково-методичній літературі підходів до розв'язування указаної суперечності:

Наша педагогічна практика засвідчує, що ознайомлення студентів-фізиків із сутністю викладених вище суперечностей, сприяє розвитку їх критичного мислення та більш 
глибокому осмисленню науково-методичних проблем у процесі самостійного вивчення СТВ і електродинаміки.

Підсумовуючи, зауважимо, що викладену вище аргументацію не слід уважати безсумнівною, варто розглядати як підгрунтя для різнобічної науково-методичної дискусії, результат якої сприяв би спростуванню проблемних питань методики навчання електродинаміки та позитивно вплинув би на якість розуміння студентами значення і ролі теоретичного й емпіричного в фізиці та методиці ії навчання.

Більш детальний аналіз щодо наявних суперечностей й непорозумінь під час вивчення електродинаміки подано в монографії [1].

\section{Література}

1. Коновал О. А. Теоретичні та методичні основи вивчення електродинаміки на засадах теорії відносності : [монографія]/ О. А. Коновал; Міністерство освіти і науки України ; Криворізький державний педагогічний університет. - Кривий Ріг : Видавничий дім, 2009. - 346 с. 2. Иродов И. Е. Электромагнетизм. Основные законы / И. Е. Иродов. - [4е изд., испр.]. - Москва: БИНОМ. Лаборатория знаний, 2003. - 320 с. 3. Коновал О. А. Основи електродинаміки : [навч. посіб для студ. вищ. пед. навч. закл.] / О. А. Коновал ; Міністерство освіти і науки України; Криворізький державний педагогічний університет. Кривий Ріг : Видавничий дім, 2008. - 347 с. 4. Сивухин Д. В. Общий курс физики : в 5 т. / Д. В. Сивухин. - Т. 3 : Электричество. - Москва : Наука, 1977. - 688 с. 5. Желеховський А. В. Курс фізики. - Вип. 3 : Електрика / А. В. Желеховський. - Харків ; Київ : держ. наук.-техн. вид-во України; ОНТИ-НКТП, 1934. - 340 с. б. Савельев И. В. Курс общей физики : в 3 т. / И. В. Савельев. - Т. 2 : Электричество и магнетизм. Волны. Оптика. Москва : Наука, 1978. - 480 с. 7. Калашников С. Г. Электричество / С. Г. Калашников. Москва : Наука, 1977. - 592 с. 8. Федорченко А. М. Теоретична фізика : [підручник] : у 2 т. / А. М. Федорченко. - Т. 1 : Класична механіка і електродинаміка. - Київ : Вища шк., 1992. 535 с. 9. Тамм И. Е. Основы теории электричества / И. Е. Тамм. - Москва : Наука, 1966. 624 с. 10. Зисман Г. А. Курс общей физики : в 3 т./ Г. А. Зисман, О. М. Тодес. - Т. 2 : Электричество и магнетизм. - Москва: Наука, 1972. - 368 с. 11. Левич В. Г. Курс теоретической физики: в 2 т. / В. Г. Левич. - Т. 1.- Москва: Наука, 1969. - 912 с. 12. Фейнман Р. Фейнмановские лекции по физике : в 9 т. / Р. Фейнман, Р. Лейтон, М. Сэндс. - Т. 5: Электричество и магнетизм. - Москва: Мир, 1966. - 290 с. 13. Угаров В. А. Специальная теория относительности / В. А. Угаров. - Москва: Наука, 1977. - 384 с. 14. Николаев Г. В. Парадокс Фейнмана и асимметрия лабораторной и движущейся систем отсчета / Г. В. Николаев. - Москва, 1975. - 20 с. - Статья деп. в ВИНИТИ, рег. №1937-75.

УДК 378:[37.011.3-051:78]

Людмила Косяк

\section{МЕТОДИЧНІ АСПЕКТИ ФОРМУВАННЯ НАВИЧОК ВОКАЛЬНО-СЛУХОВОГО САМОКОНТРОЛЮ В МАЙБУТНІХ УЧИТЕЛІВ МУЗИЧНОГО МИСТЕЦТВА У КЛАСІ ПОСТАНОВКИ ГОЛОСУ}

Косяк Л. I. Методичні аспекти формування навичок вокально-слухового самоконтролю в майбутніх учителів музичного мистецтва у класі постановки голосу.

У статті доведено актуальність дослідження, розкрито сутність вокально-слухового самоконтролю, структуру якого складають слухові, м'язові, вібраційні й емоційні 